\title{
The Air-Water Interface of Water Microdroplets Formed by Ultrasonication or Condensation Does Not Produce $\mathrm{H}_{2} \mathrm{O}_{2}$
}

\author{
Nayara H. Musskopf, ${ }^{\dagger}$ Adair Gallo, Jr., ${ }^{\dagger}$ Peng Zhang, ${ }^{\dagger}$ Jeferson Petry, and Himanshu Mishra*
}

Cite This: J. Phys. Chem. Lett. 2021, 12, 11422-11429

Read Online

\begin{abstract}
Recent reports on the production of hydrogen peroxide $\left(\mathrm{H}_{2} \mathrm{O}_{2}\right)$ on the surface of condensed water microdroplets without the addition of catalysts or additives have sparked significant interest. The underlying mechanism is thought to be ultrahigh electric fields at the air-water interface; smaller droplets present larger interfacial areas and produce higher (detectable) $\mathrm{H}_{2} \mathrm{O}_{2}$ yields. To gain insights into this phenomenon, we performed condensation experiments and quantified $\mathrm{H}_{2} \mathrm{O}_{2}$ formation as a function of the vapor source. Specifically, we compared the $\mathrm{H}_{2} \mathrm{O}_{2}$ concentration in water microdroplets condensed from the vapor realized via (i) heating water in the range of $50-70{ }^{\circ} \mathrm{C}$ and (ii) ultrasonic humidification (as exploited in the original report). Experimental results revealed that the $\mathrm{H}_{2} \mathrm{O}_{2}$ level inside water microdroplets condensed via heating water was below our detection limit $(\geq 0.25 \mu \mathrm{M})$, regardless of the droplet size or the substrate wettability. In contrast, water droplets condensed via ultrasonic humidification contained significantly higher $(\sim 1 \mu \mathrm{M}) \mathrm{H}_{2} \mathrm{O}_{2}$ concentrations. We conclude that the ultrasonic humidifiers contribute to $\mathrm{H}_{2} \mathrm{O}_{2}$ production, not droplet interfacial effects.
\end{abstract}

$\mathrm{R}$ ecent studies reporting on the spontaneous production of $\leq 115 \mu \mathrm{M} \mathrm{H}_{2} \mathrm{O}_{2}$ in condensed water microdroplets with diameters of $\leq 10 \mu \mathrm{m}$ on common substrates have sparked considerable interest. ${ }^{1}$ Elucidation of the breakage of water O$\mathrm{H}$ covalent bonds under normal temperature and pressure (NTP, $293 \mathrm{~K}$ and $1 \mathrm{~atm}$ ) without the use of a catalyst, energy (electrical or mechanical), or other chemicals poses a challenge to our current understanding of water. These findings could advance our understanding of environmental processes, such as the oxidation of $\mathrm{S}(\mathrm{IV})$ species by $\mathrm{H}_{2} \mathrm{O}_{2}$ in the presence or absence of $\mathrm{Fe}^{2+}$ or $\mathrm{Cu}^{2+}$ ions, leading to the acidification of clouds, dew, fog, etc. ${ }^{2-4}$ Greener approaches for $\mathrm{H}_{2} \mathrm{O}_{2}$ synthesis $^{5}$ and the rational development of hydrogen peroxide-based automated room disinfection in hospitals, ${ }^{6}$ water treatment, ${ }^{7}$ oral care, ${ }^{8}$ etc., are other exciting avenues. The mechanism suggested for $\mathrm{H}_{2} \mathrm{O}_{2}$ production in water microdroplets is based on the presence an an ultrahigh electric field at the air-water interface $\left(\sim 10^{7} \mathrm{~V} / \mathrm{cm}\right)$, which drives the formation of $\bullet \mathrm{OH}$ radicals from $\mathrm{OH}^{-}$ions; these $\bullet \mathrm{OH}$ radicals combine to form $\mathrm{H}_{2} \mathrm{O}_{2}{ }^{1,9}$ Currently, there is no theoretical explanation available for this intriguing phenomenon. We note that probing the air-water interface of $<1 \mathrm{~nm}$ dimensions is a daunting task and sometimes fraught with interpretational ambiguities and/or experimental artifacts. ${ }^{10-19}$

Let us begin by briefly discussing the significance of the microscale of water droplets implicated in this phenomenon. Microscale enhances the air-water surface area; the larger the droplet surface area, the higher the level of $\mathrm{H}_{2} \mathrm{O}_{2}$ production due to the putative surface electrical field. ${ }^{1}$ For example, the surface area of a $1 \mathrm{~mL}$ water droplet at normal temperature and pressure (NTP, $293 \mathrm{~K}$ and $1 \mathrm{~atm}$ ) with a diameter $D$ of 1.24 $\mathrm{cm}$, if transformed into microdroplets with a diameter $d$ of 5 $\mu \mathrm{m}$, increases by a factor of $\mathrm{D} / d=2480$. In summary, the claim essentially is that $\mathrm{H}_{2} \mathrm{O}_{2}$ is produced even on the surface of a pail of water but remains undetected owing to the small airwater surface area and large volume of water, yielding ultralow concentrations. ${ }^{1}$ The maximum reported $\mathrm{H}_{2} \mathrm{O}_{2}$ concentration in the water microdroplets condensed from the vapor within the relative humidity $(\mathrm{RH})$ range of $40-70 \%$ and at substrate (silica) temperature $3.5{ }^{\circ} \mathrm{C}$ is $\sim 115 \mu \mathrm{M}$, when the droplet mean size is $\leq 10 \mu \mathrm{m}$. ${ }^{1}$ This concentration translates to $\sim 1$ $\mathrm{H}_{2} \mathrm{O}_{2}$ molecule per $\sim 483092$ water molecules, which renders standard spectroscopic fingerprinting techniques ineffective. As the condensed droplets grow over time, their surface-tovolume ratios decrease, which reduces $\mathrm{H}_{2} \mathrm{O}_{2}$ production and lowers measurable $\mathrm{H}_{2} \mathrm{O}_{2}$ concentration. ${ }^{1}$ Thus, it is crucial to utilize ultrasensitive detection methods to investigate the factors and mechanisms underlying this phenomenon. Herein, we investigate $\mathrm{H}_{2} \mathrm{O}_{2}$ in condensed water microdroplets via an ultrasensitive method and put forth an alternate explanation for $\mathrm{H}_{2} \mathrm{O}_{2}$ formation in condensed water microdroplets.

Received: September 7, 2021

Accepted: November 1, 2021 
(A)
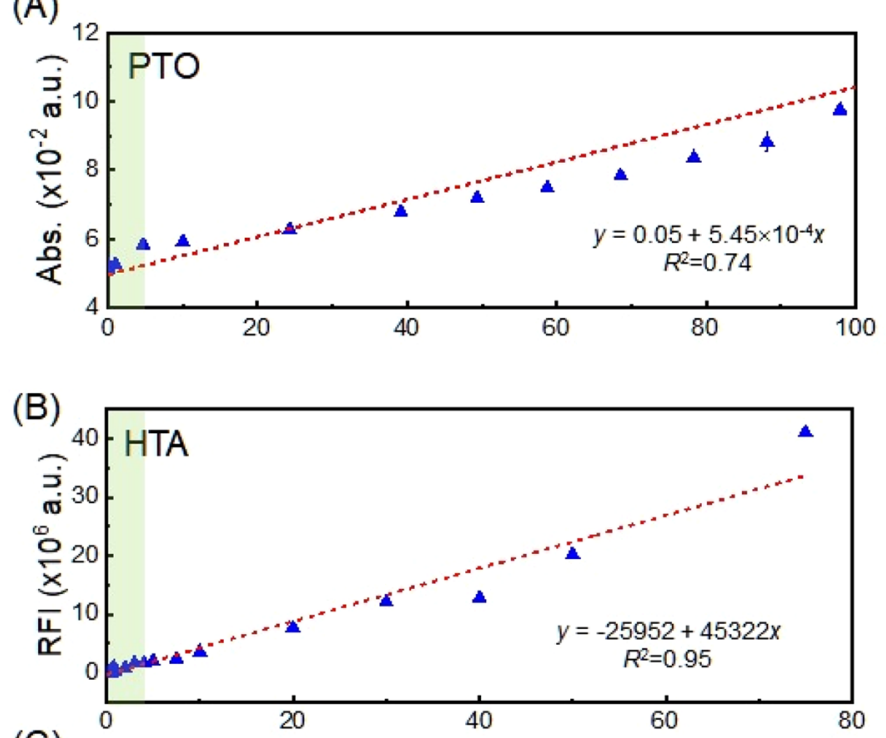

(C)

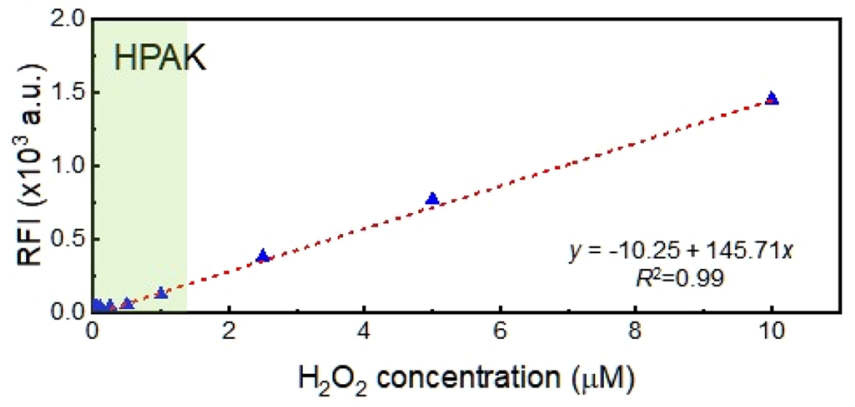

(D)
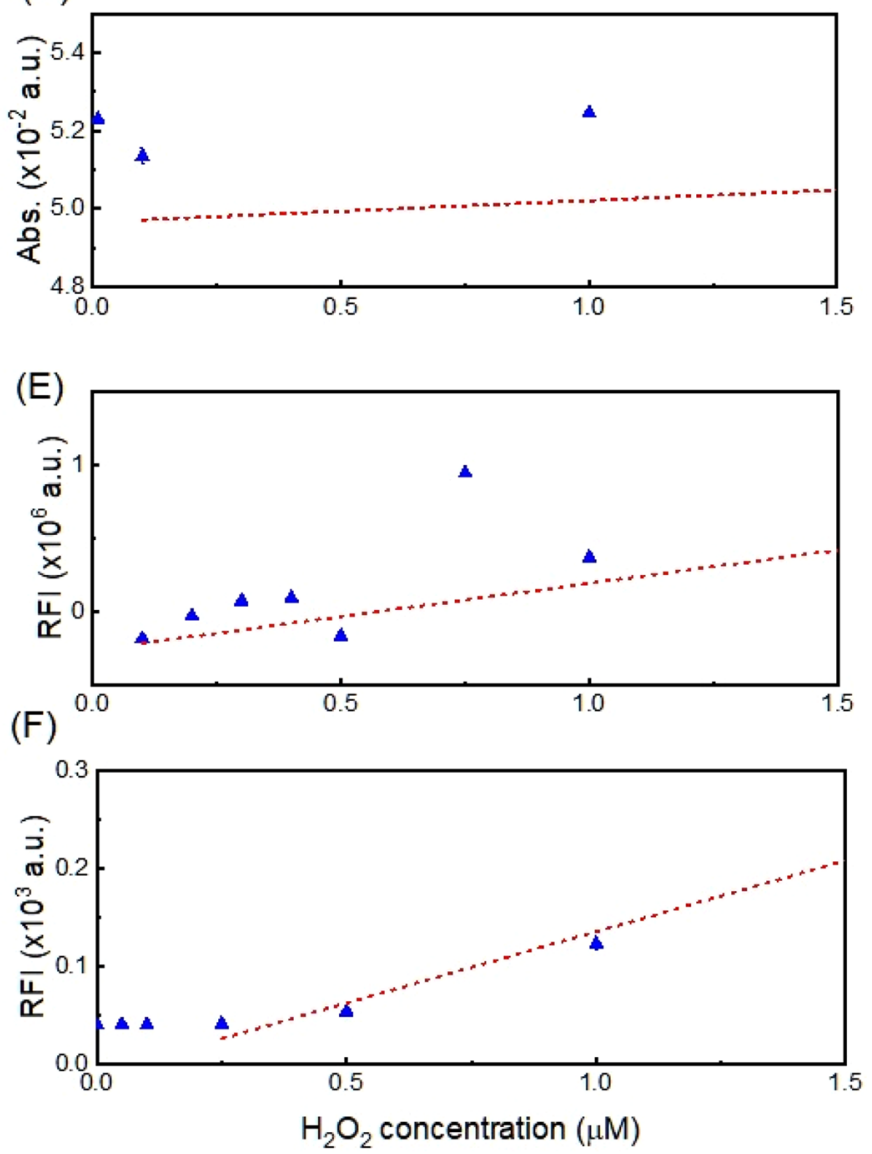

Figure 1. Comparison of representative calibration curves for $\mathrm{H}_{2} \mathrm{O}_{2}$ quantification assays: (A) potassium titanium oxalate (PTO) assay, (B) 2hydroxyterephthalic acid (HTA) assay, and (C) hydrogen peroxide assay kit (HPAK). The HPAK can detect $\mathrm{H}_{2} \mathrm{O}_{2}$ concentrations down to 250 $\mathrm{nM}$, while the PTO and HTA assays fail to resolve at 10 and $5 \mu \mathrm{M}$, respectively. In the range of $0-1 \mu \mathrm{M}$, (D) PTO and (E) HTA assays cannot afford linearity in quantification, whereas (F) the HPAK affords it reliably for $\geq 250 \mathrm{nM} \mathrm{H}_{2} \mathrm{O}_{2}$.

To utilize the most sensitive analytical method for quantifying trace amounts of $\mathrm{H}_{2} \mathrm{O}_{2}$ in water, we compared the efficacy of several known methods. ${ }^{3}$ For instance, titration with $0.1 \mathrm{M}$ potassium titanium oxalate [PTO, $\mathrm{K}_{2} \mathrm{TiO}\left(\mathrm{C}_{2} \mathrm{O}_{4}\right)_{2}$ ] is the most common method that was also exploited in the original report. ${ }^{1}$ It entails the measurement of the absorbance at $400 \mathrm{~nm}$ of samples that also contain PTO (Figure S1A). However, this method can at best detect $\sim 10 \mu \mathrm{M} \mathrm{H}_{2} \mathrm{O}_{2}$ (or $\sim 0.34 \mathrm{ppm}$ ) (Figure 1A). We also tested the efficacy of titration with terephthalic acid that yields 2-hydroxyterephthalic acid (HTA) on reaction with $\bullet \mathrm{OH}$ radicals furnished by $\mathrm{H}_{2} \mathrm{O}_{2}{ }^{20}$ However, this method also fails to resolve dissolved $\mathrm{H}_{2} \mathrm{O}_{2}$ concentrations below $5 \mu \mathrm{M}$ (or $\sim 0.17 \mathrm{ppm}$ ) (Figure $1 \mathrm{~B}$ and Figure S1B). Either method would, for instance, prove to be inadequate in providing high-resolution insight into the time-dependent decline in the $\mathrm{H}_{2} \mathrm{O}_{2}$ concentration in condensing drops as they grow larger. In response, we utilized the Hydrogen Peroxide Assay Kit (HPAK, ab138886, Abcam PLC, Cambridge, U.K.). This fluorometric kit contains (i) a proprietary peroxide indicator that upon oxidation with $\mathrm{H}_{2} \mathrm{O}_{2}$ produces fluorescence in the near-infrared region $(674 \mathrm{~nm}$ wavelength) and (ii) the horseradish peroxidase (HRP) enzyme that catalyzes the oxidation reaction. The HRP's catalytic activity enhances the fluorescence signal significantly, facilitating a linear detection range for $\mathrm{H}_{2} \mathrm{O}_{2}$ from $\sim 250 \mathrm{nM}$ (or $8.5 \mathrm{ppb}$ ) to $10 \mu \mathrm{M}(0.3 \mathrm{ppm}$ ) and rendering HPAK one of the most sensitive quantification methods for $\mathrm{H}_{2} \mathrm{O}_{2} \cdot{ }^{3,21}$ Panels A-C of Figure 1 compare the calibration plots for $\mathrm{H}_{2} \mathrm{O}_{2}$ titrations with PTO, terephthalic acid, and HPAK methods, respectively. With an approximately 40 times lower limit of detection than the PTO method, the HPAK assay would be able to pinpoint $\mathrm{H}_{2} \mathrm{O}_{2}$ concentrations inside condensing water droplets as their volumes increase with time (despite the dilution).

Equipped with the HPAK assay, we investigated $\mathrm{H}_{2} \mathrm{O}_{2}$ production in condensed water microdroplets as a function of different (i) methods for producing water vapor, (ii) substrates for condensation, and (iii) droplet sizes. Experiments were conducted inside a clean glovebox equipped with a $\mathrm{N}_{2}$ flow to control the relative humidity of air. Water vapor was produced inside the glovebox via (i) a commercial ultrasonic humidifier ( $15 \mathrm{~W}$ output power) equipped with a megahertz range piezoelectric transducer or (ii) a hot plate to heat water in the range of $50-70{ }^{\circ} \mathrm{C}$ (Materials and Methods). N.B. an ultrasonic humidifier is a common household appliance; it produces tiny droplets at the air-water interface that rapidly evaporate to increase the relative humidity; a similar instrument was exploited in the original report. ${ }^{1}$ In both cases, the relative humidity was adjusted to $92-96 \%$ at $\sim 21-$ $23{ }^{\circ} \mathrm{C}$ by a moisture controller by flowing $\mathrm{N}_{2}$ gas into the glovebox whenever the humidity was above the set point. Single-crystal $\mathrm{SiO}_{2} / \mathrm{Si}$ wafers with the following surface 

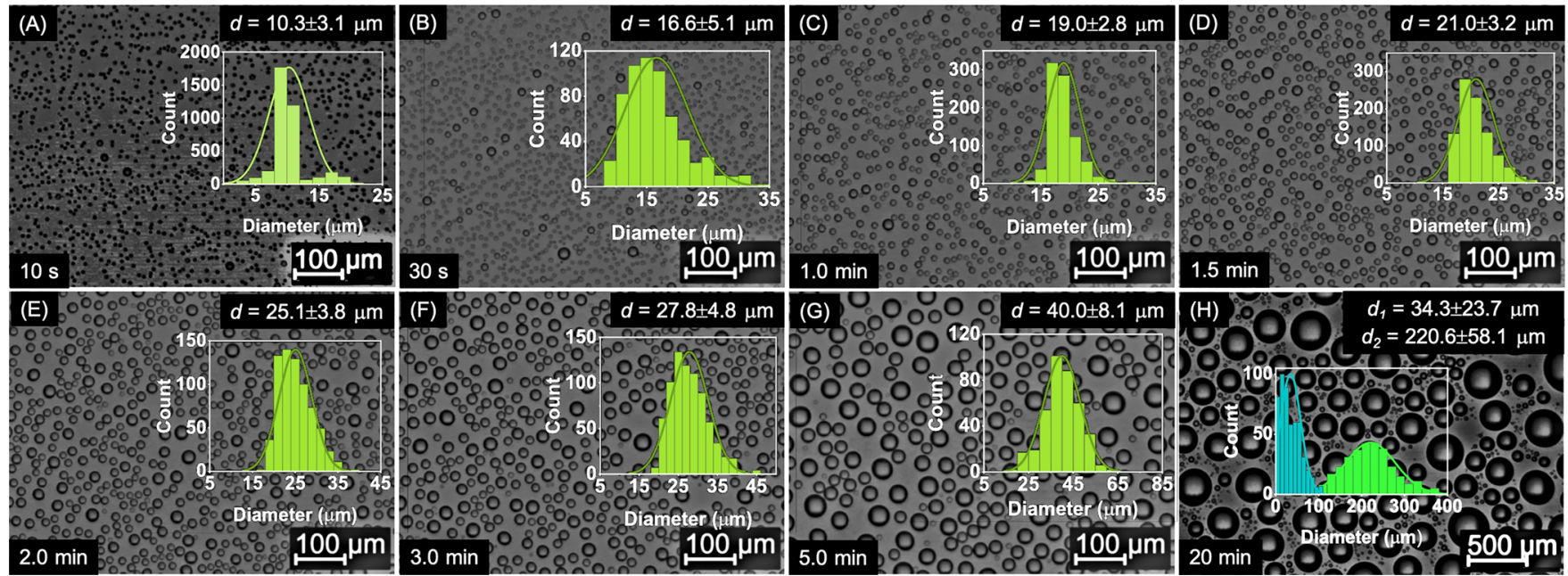

Figure 2. Representative time-dependent size distributions of condensed water droplets on FDTS-coated silica surfaces maintained at 3-4 ${ }^{\circ} \mathrm{C}$ and 92-96\% RH realized via an ultrasonic humidifier: (A) $10 \mathrm{~s}$, (B) $30 \mathrm{~s}$, (C) $1 \mathrm{~min}$, (D) $1.5 \mathrm{~min}$, (E) $2.0 \mathrm{~min},(\mathrm{~F}) 3.0 \mathrm{~min}$, (G) $5 \mathrm{~min}$, and (H) 40 min (bimodal distribution). Note that scale bars are in micrometers.
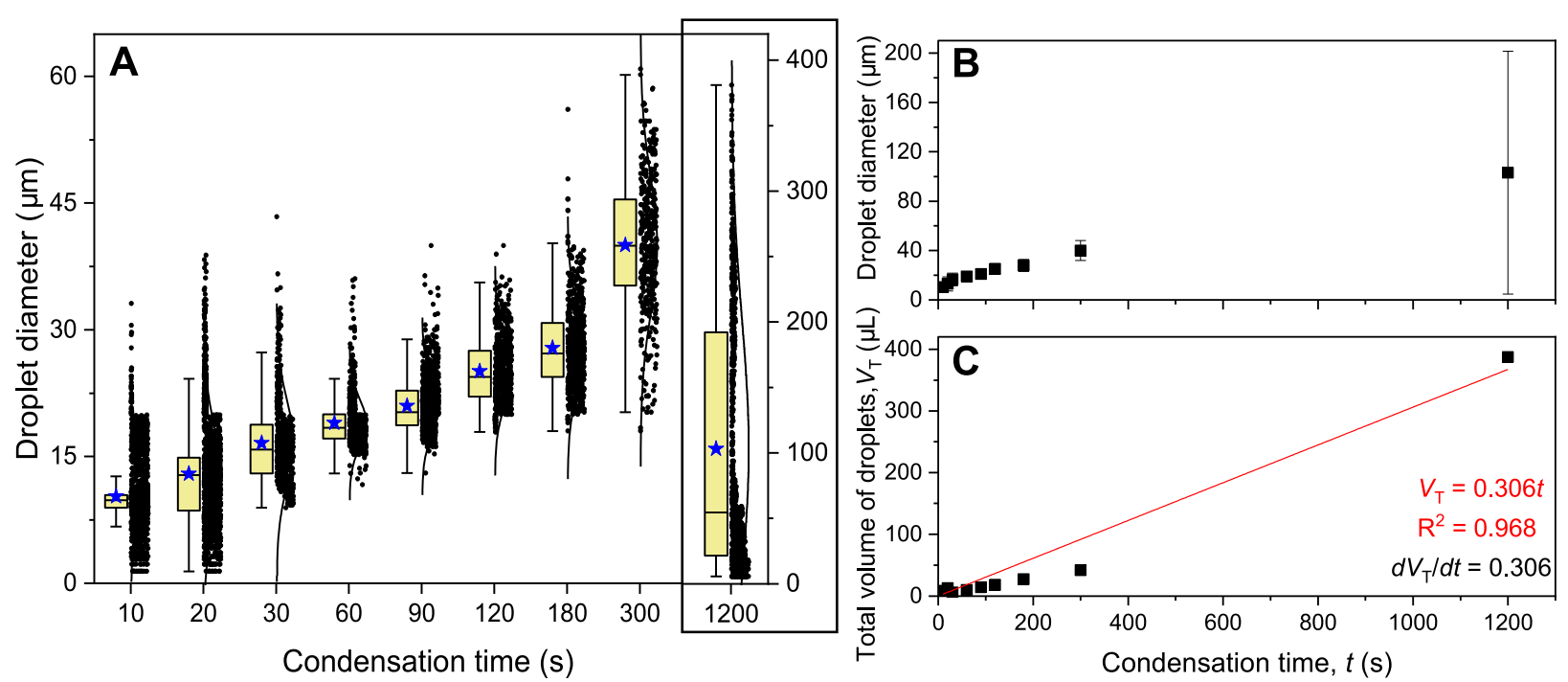

Figure 3. Representative image analysis (with Image ${ }^{24}$ ) of condensed water droplets on FDTS-coated silica surfaces at 3-4 ${ }^{\circ} \mathrm{C}$ and $92-96 \%$ RH realized via an ultrasonic humidifier. (A) Diameter distribution of the condensed droplets as a function of time [note that blue stars correspond to the mean value; the $x$-axis scale is not linear, and the right-hand-side $y$-axis is droplet diameter (micrometers) for $t=1200 \mathrm{~s}$ only]. (B) Mean droplet diameters as a function of time. Error bars signify one standard deviation. (C) Estimated cumulative volume of the condensate over time. The estimated average condensation rate is $0.31 \mu \mathrm{L} / \mathrm{s}$. Note the bimodal droplet distribution at $t=1200 \mathrm{~s}$; this happens because larger droplets merge and numerous $\leq 10 \mu \mathrm{m}$ droplets emerge in the spaces between them.

treatment (wettability) served as the substrates for the condensation of water vapor: (i) oxygen plasma treatment (hydrophilic) and (ii) silanization with perfluorodecyltrichlorosilane (FDTS) using a molecular vapor deposition technique $^{22}$ (hydrophobic; details in the Materials and Methods and wetting characterization in section S1 of the Supporting Information). Substrates were cooled below the dew point by placing them on a water-ice bag; the surface temperatures were measured using an infrared probe (Materials and Methods) and found to be in the range of $3-4{ }^{\circ} \mathrm{C}$. A significant distance $(\sim 40 \mathrm{~cm})$ between the location of the substrates inside the glovebox and the vapor source ensured that any airborne droplets and/or clusters would evaporate first to form vapor and then condense, as observed by the gradual increase in the size of the droplets (Figure 2 and Figure S2). Note that hydrophobic FDTS-coated $\mathrm{SiO}_{2} / \mathrm{Si}$ wafers (hereafter termed FDTS-coated silica) were utilized as the substrate for condensation in most of this work because they facilitated easier removal of the condensed water for further analysis than did hydrophilic plasma-treated silica.

With the water vapor supplied from the ultrasonic humidifier, size distributions (mean \pm standard deviation) of the condensed microdroplets on FDTS-coated silica shifted their peak positions from $10.3 \pm 3.2 \mu \mathrm{m}$ at $10 \mathrm{~s}$ to $103 \pm 98$ $\mu \mathrm{m}$ (bimodal distribution) at $20 \mathrm{~min}$ (Figures 2 and 3 and details in Materials and Methods). Similarly, with the vapor supplied from the heated water $\left(60{ }^{\circ} \mathrm{C}\right)$, size distributions shifted their peak positions from $8.4 \pm 2.7 \mu \mathrm{m}$ at $10 \mathrm{~s}$ to $144 \pm$ $134 \mu \mathrm{m}$ (bimodal distribution) at $40 \mathrm{~min}$ (Figures S2 and S3).

We were also able to estimate the condensation rates via image analysis. To do this, we assumed the condensed microdroplets to be truncated spheres with the contact angles 
at the solid-liquid-vapor interface equal to the measured apparent contact angles on FDTS-coated silica $\left[\theta_{\mathrm{r}} \approx 105^{\circ}\right.$ (section S1)]. This is a reasonable assumption because the capillary length of water, defined as the length scale at which capillary forces dominate over inertia, at NTP is $\lambda_{c}=2.7 \mathrm{~mm}$, which is much larger than the size of the condensed water microdroplets. N.B. $\lambda_{\mathrm{c}}$ is given by the formula, $\lambda_{\mathrm{c}}=\sqrt{\frac{\gamma_{\mathrm{LV}}}{\rho g}}$, where, $\gamma_{\mathrm{LV}}$ is the surface tension of water, $\rho$ is the density, and $g$ is the acceleration due to gravity. ${ }^{23}$ With this approach, we estimated the condensation rates to be 0.31 and $0.23 \mu \mathrm{L} / \mathrm{s}$ for the ultrasonic humidifier and the heating plate $\left(\right.$ at $60{ }^{\circ} \mathrm{C}$ ), respectively (Figure 3 and Figure S3). Out of curiosity, we also quantified the condensation behavior of water from the ambient laboratory air at $59 \% \mathrm{RH}$ and $21.4{ }^{\circ} \mathrm{C}$ and found it to be $0.35 \mu \mathrm{L} / \mathrm{s}$ (Figures S4 and S5).

Next, $\mathrm{H}_{2} \mathrm{O}_{2}$ concentrations were quantified in the condensates formed on FDTS-coated silica and plasma-treated silica with the vapor formed via heating water or ultrasonic humidification (Figure 3). In a typical experiment, we stopped water condensation when the condensate was enough for us to collect $\sim 400-600 \mu \mathrm{L}$, which took $\sim 40$ min for heating and $\sim 20 \mathrm{~min}$ for the ultrasonic humidifier. See Figure $3 \mathrm{~A}$ and Figure S3A to notice the size distribution of droplets in those instances. Subsequently, the substrates were tilted to pour condensed water (drops or films) into clean glassware for $\mathrm{H}_{2} \mathrm{O}_{2}$ quantification via the HPAK. When water was heated to $60{ }^{\circ} \mathrm{C}$ to produce the vapor, we found no significant differences (with a $p$ value of >0.01) in the $\mathrm{H}_{2} \mathrm{O}_{2}$ concentrations of the condensed water and the bulk water; i.e., both were below our detection limit $(0.25 \mu \mathrm{M})$ (Figure 4, group c, and Figure S8). Also, when the vapor was formed via heating water, the hydrophilicity or hydrophobicity of the substrates had no effect on the $\mathrm{H}_{2} \mathrm{O}_{2}$ concentration. These trends were consistent at 50 and $70^{\circ} \mathrm{C}$, as well (Figure S6).

In contrast, when ultrasonic humidification was exploited to produce the vapor, there was a significant enhancement in the $\mathrm{H}_{2} \mathrm{O}_{2}$ concentration $(\sim 1 \mu \mathrm{M})$ in the condensed water (Figure 4); the condensates on the plasma-treated surfaces had $\mathrm{H}_{2} \mathrm{O}_{2}$ concentrations slightly higher than those on the FDTS-coated surfaces (groups $\mathbf{a}$ and $\mathbf{b}$ in Figure 4).

We wondered if the absence of $\mathrm{H}_{2} \mathrm{O}_{2}$ in the condensates derived from the heating experiments and the $\sim 1 \mu \mathrm{M} \mathrm{H}_{2} \mathrm{O}_{2}$ concentration measured in the condensates derived from the ultrasonic humidifier were so low due to the fact that (i) we collected microdroplets largely with diameters of $\geq 10 \mu \mathrm{m}$, which caused a dramatic dilution of the $\mathrm{H}_{2} \mathrm{O}_{2}$ concentration, or (ii) $\mathrm{H}_{2} \mathrm{O}_{2}$ is produced exclusively when ultrasonic humidification is applied.

To pinpoint the correct answer, first, we tried to measure the $\mathrm{H}_{2} \mathrm{O}_{2}$ concentration in water microdroplets with diameters of strictly $\leq 10 \mu \mathrm{m}$. Under our experimental conditions, condensed water microdroplets with diameters of $\leq 10 \mu \mathrm{m}$ appeared during the first $10 \mathrm{~s}$ for the ultrasonic humidifier (Figures 2 and 3 ) and during the first $20 \mathrm{~s}$ for the heating plate at $60{ }^{\circ} \mathrm{C}$ (Figures S2 and S3) and ambient moisture condensation (Figures S4 and S5). Very quickly, we realized that due to their size being significantly smaller than the capillary length of water, pinning forces were so high compared to inertia that it was not possible to detach them via tilting $\left(90^{\circ}\right.$ or $\left.180^{\circ}\right)$ from the FDTS-coated silica substrates. ${ }^{23}$ Microdroplets also evaporated rapidly when exposed to a lower-relative humidity environment, which prevented us from

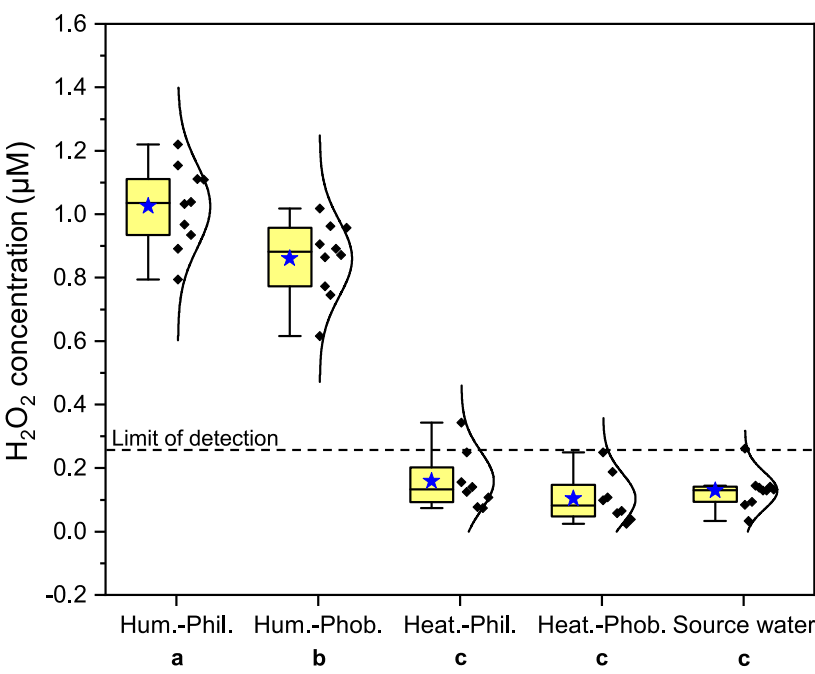

Figure 4. Comparison of $\mathrm{H}_{2} \mathrm{O}_{2}$ concentrations in the water microdroplets that accumulated on hydrophobic (Phob.) and hydrophilic (Phil.) substrates after the condensation of vapor produced via (i) heating water in the temperature range of 50-70 ${ }^{\circ} \mathrm{C}$ (Heat.) and (ii) an ultrasonic humidifier (Hum.). There were no statistically significant differences in the $\mathrm{H}_{2} \mathrm{O}_{2}$ concentration of the bulk water and the water droplets collected after the condensation of vapor generated by heating water at $60{ }^{\circ} \mathrm{C}$. Note that experimental results for heating at 50 and $70{ }^{\circ} \mathrm{C}$ (Figure S6) yield results similar to those of the $60^{\circ} \mathrm{C}$ case presented here. The chemical makeup of the substrates had no significant effects on the $\mathrm{H}_{2} \mathrm{O}_{2}$ concentration. In contrast, the $\mathrm{H}_{2} \mathrm{O}_{2}$ concentration in the water condensed from the ultrasonic humidifier was $\sim 1 \mu \mathrm{M}$. In this case, the chemical makeup of the substrates also had a significant effect on the $\mathrm{H}_{2} \mathrm{O}_{2}$ concentration. Bold letters $(\mathbf{a}-\mathbf{c})$ under the labels refer to the statistically different groups analyzed with one-way ANOVA and Tukey's test for comparison of the means $(p<0.01)$; a blue star indicates the mean value. Note that the detection limit of the HPAK assay in our experiments was $0.25 \mu \mathrm{M}$.

using ultracentrifugation for sliding and collecting them. Furthermore, the volume of the droplets after condensation for only $10-20 \mathrm{~s}$ was so low that the HPAK could not be utilized because the minimum sample volume, considering evaporative losses during handling, is $400-600 \mu \mathrm{L}$. Therefore, we resorted to commercial peroxide test strips with a detection limit of $29.4 \mu \mathrm{M}$ for aqueous $\mathrm{H}_{2} \mathrm{O}_{2}$; similar strips were also utilized in the original report ${ }^{1}$ (details in Materials and Methods). However, when peroxide test strips were swiped over water microdroplets with diameters of $\leq 10 \mu \mathrm{m}$ that condensed from vapor generated by the ultrasonic humidifier, heating $\left(60^{\circ} \mathrm{C}\right)$, and ambient air, they did not undergo any change in their color. As a check, we tested the test strips with standard $\mathrm{H}_{2} \mathrm{O}_{2}$ solutions and confirmed that they reliably detect $\mathrm{H}_{2} \mathrm{O}_{2}$ at concentrations of $\geq 30 \mu \mathrm{M}$.

We wondered if this outcome was due to the fact that the lifetime of the microdroplets was too short to produce a detectable $\mathrm{H}_{2} \mathrm{O}_{2}$ concentration. After the first few seconds (7$10 \mathrm{~s}$ ) of condensation from the three sources listed above, we cut off the vapor from condensing further by placing a lid on top. This simple method allowed us to maintain the desirable size distribution for a longer time $(2-5 \mathrm{~min})$. Using peroxide test strips again, we found no evidence of aqueous $\mathrm{H}_{2} \mathrm{O}_{2}$ regardless of the waiting time.

Next, we studied the effects of the output power of ultrasonic humidifiers on the $\mathrm{H}_{2} \mathrm{O}_{2}$ concentration in condensed water microdroplets. We compared the perform- 
ance of our $15 \mathrm{~W}$ ultrasonic humidifier with that of another commercial $20 \mathrm{~W}$ device (details in Materials and Methods). We broadened the investigation by probing $\mathrm{H}_{2} \mathrm{O}_{2}$ concentrations not only in the condensed microdroplets but also in the mist formed at the humidifier outlet as well as the water reservoirs inside the humidifiers. Because the volumes of the mist and the water reservoirs were large, we could track them from inception via the HPAK, while we had to wait for $\sim 20$ min to collect adequate condensate (also explained above). Experimental results revealed that for either device, the $\mathrm{H}_{2} \mathrm{O}_{2}$ concentration was below the detection limit before it was turned on; after mist formation started, the $\mathrm{H}_{2} \mathrm{O}_{2}$ concentration in the mist increased with time and reached $\sim 2$ and $\sim 3$ $\mu \mathrm{M}$ for the 15 and $20 \mathrm{~W}$ devices, respectively (Figure 5). The $\mathrm{H}_{2} \mathrm{O}_{2}$ concentrations in the reservoir also followed the same trend.

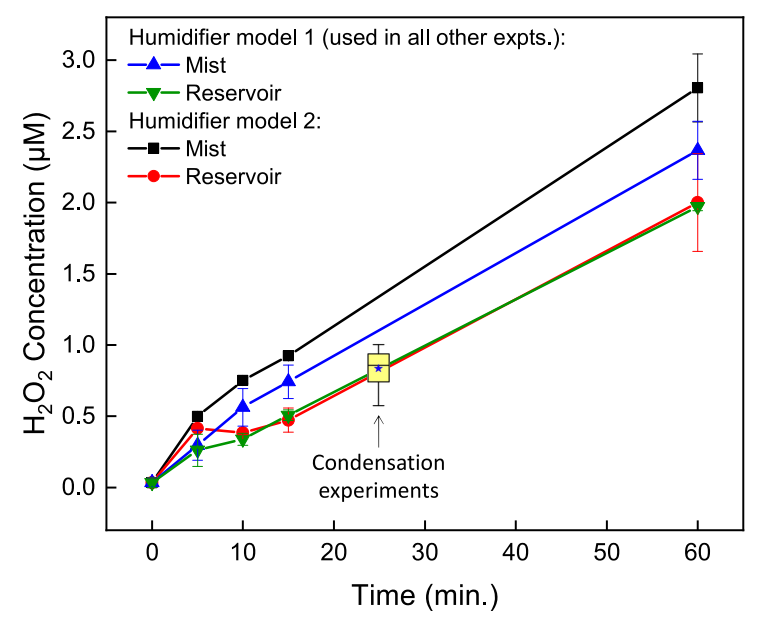

Figure 5. Ultrasonic humidifier mist and $\mathrm{H}_{2} \mathrm{O}_{2}$ formation. $\mathrm{H}_{2} \mathrm{O}_{2}$ formation over time in the mist and in the water reservoir (in contact with the piezo element) in ultrasonic humidifier models 1 and 2 with output powers of 15 and $20 \mathrm{~W}$, respectively. The yellow box represents the $\mathrm{H}_{2} \mathrm{O}_{2}$ concentrations in water microdroplets that accumulated on FDTS-coated silica (from Figure 4). Note that humidifier model 1 was used in most of the condensation experiments reported in this work and humidifier model 2 was used to compare the effect of output power on $\mathrm{H}_{2} \mathrm{O}_{2}$ production.

We also tested the effects of a $500 \mathrm{~W}$ microtip ultrasonication device $(20000 \mathrm{~Hz})$ on $\mathrm{H}_{2} \mathrm{O}_{2}$ concentration in bulk water (Materials and Methods). Analysis with the HPAK revealed that while the bulk water had an initial $\mathrm{H}_{2} \mathrm{O}_{2}$ concentration below the detection limit, it increased linearly with time to $3 \mu \mathrm{M}$ in $3 \mathrm{~h}$ (Figure S7).

As illustrated in Figure 6, our experiments with heating, ultrasonic humidifiers, and ambient air condensation demonstrate that detectable $\mathrm{H}_{2} \mathrm{O}_{2}$ is produced in condensed water microdroplets exclusively when ultrasonic humidifiers are exploited. In section S2, we explain why condensed microdroplets with diameters of $\leq 10 \mu \mathrm{m}$ produced via heating, ultrasonics, and ambient air could not have had $\mathrm{H}_{2} \mathrm{O}_{2}$ concentrations of $\geq 60 \mu \mathrm{M}$ in our experiments, or else the HPAK would have detected them. Furthermore, during ultrasonic humidification studies, we noticed that most of the generated mist fell back into the water reservoir, which caused the time-dependent increase in the $\mathrm{H}_{2} \mathrm{O}_{2}$ concentration in the mist. This is expected to increase the $\mathrm{H}_{2} \mathrm{O}_{2}$ concentration in the condensate for some time, a trend also observed in the original report. ${ }^{1}$ For further insight into $\mathrm{H}_{2} \mathrm{O}_{2}$ production in ultrasonic humidifiers, it is crucial to investigate the effects of output power, operational frequency, structural design, water level, etc. How $\mathrm{H}_{2} \mathrm{O}_{2}$ partitions between the mist and the bulk water considering its ultrahigh solubility in water is also worth exploring. Next, we list two crucial questions pertaining to $\mathrm{H}_{2} \mathrm{O}_{2}$ formation that still remain unaddressed. (i) Why do we not observe $\mathrm{H}_{2} \mathrm{O}_{2}$ concentration in the range of $30-115 \mu \mathrm{M}$ in our condensed microdroplets as in the original report? ${ }^{1}$ (ii) What factors and mechanisms underlie the formation of $\mathrm{H}_{2} \mathrm{O}_{2}$ $(\sim 30 \mu \mathrm{M})$ in water microdroplets generated via pneumatic spraying $^{26}$ (which does not utilize ultrasonication for droplet generation)? We are currently investigating these unanswered questions via a combination of experiment and theory.

Significantly different outcomes manifest when a bulk liquid is exposed to ultrasonication or gently heated on a hot plate (below its boiling point and with a stirrer). The latter method distributes the energy uniformly within the bulk, while the former entails energy localization leading to hot spots. ${ }^{27}$ The ultrasonication of water causes the formation of numerous tiny pulsating bubbles, cavitation, that eventually implode to produce ultrahigh pressure (shock waves) and temperature and drive chemical reactions (including $\mathrm{H}_{2} \mathrm{O}_{2}$ formation). ${ }^{28-30}$ On one hand, cavitation erosion of surfaces poses an engineering challenge to fluid machinery; ${ }^{31,32}$ on the other hand, it has been utilized for wastewater treatment, ${ }^{33,7,34,35}$ surface cleaning, ${ }^{36}$ and synthesis of materials. ${ }^{37}$ Similarly, ultrasonic humidifiers exploit megahertz-frequency piezoelectric transducers that convert electrical energy into vibrational energy to produce the mist. Our experimental results demonstrate that this process produces $\mathrm{H}_{2} \mathrm{O}_{2}$ in the mist and, consequently, in the condensed droplets (Figure 5). In contrast, mild heating does not lead to $\mathrm{H}_{2} \mathrm{O}_{2}$ formation (Figure 4). Therefore, we submit that the recently reported $\mathrm{H}_{2} \mathrm{O}_{2}$ production in condensed water droplets could be in part due to experimental artifacts arising from ultrasonication. ${ }^{1} \mathrm{We}$ hope that this report will stimulate further research to address the pending questions.

\section{MATERIALS AND METHODS}

Chemicals. A Milli-Q Advantage 10 setup was utilized for deionized water used in this study. The water purification unit consisted of a Q-Gard pretreatment pack, an ultraviolet lamp, a Quantum cartridge (activated carbon and ion exchange resins), and a Q-Pod dispenser for the final polishing. ${ }^{38}$ The electrical resistivity of the water was $18.2 \mathrm{M} \Omega \mathrm{cm}$. Standard hydrogen peroxide $\left(\mathrm{H}_{2} \mathrm{O}_{2}\right)$ solutions $(30 \%)$ were purchased from VWR Chemicals (catalog no. 23622.298) and used as is.

Substrates for Condensation. Silicon wafers (p-doped, $\langle 100\rangle$ orientation, $4 \mathrm{in}$. diameter, with a $500 \mu \mathrm{m}$ thickness and with a thermally grown $2 \mu \mathrm{m}$ thick oxide layer) were purchased from Silicon Valley Microelectronics (catalog no. SV010).

Functionalization of $\mathrm{SiO}_{2} / \mathrm{Si}$ Wafers. Oxygen Plasma Treatment for Hydrophilic Substrates. A Diener electronic machine (Atto model, $200 \mathrm{~W}$ ) was supplied with ultrapure (99.999\%) $\mathrm{O}_{2}$ gas at a flow rate of $16.5 \mathrm{sccm}$ for $10 \mathrm{~min}$, to create oxygen plasma.

Silanization with Perfluorodecyltrichlorosilane (FDTS). Treatment of silica surfaces with an oxygen plasma for $2 \mathrm{~min}$ removed organic contaminants and hydroxylated the surface. These surfaces were then grafted with FDTS using a molecular vapor deposition process (Applied Microstructures 


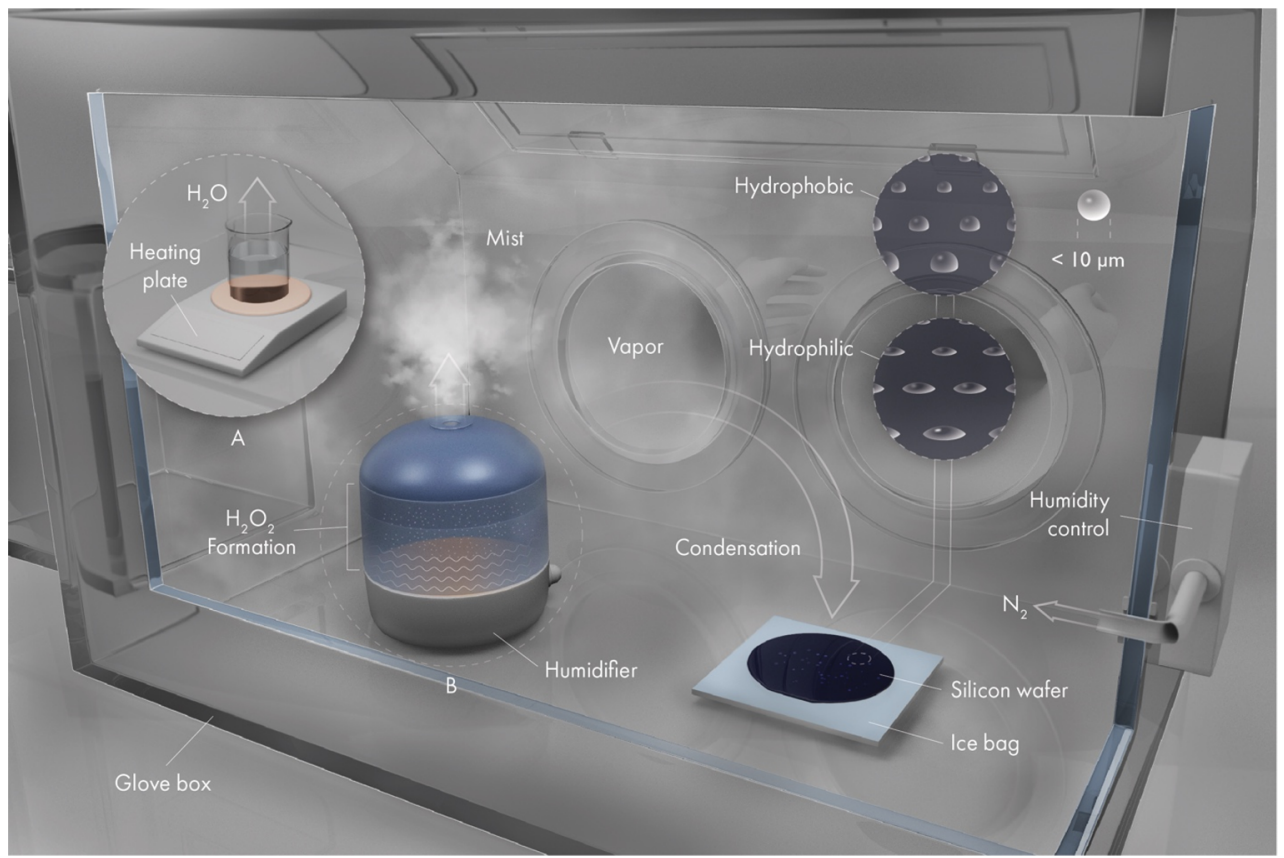

Figure 6. Scientific illustration of the condensation of water vapor generated via (A) heating water on a hot plate and (B) an ultrasonic humidifier. Condensed water droplets formed on hydrophilic and hydrophobic substrates and then were collected and analyzed for $\mathrm{H}_{2} \mathrm{O}_{2}$ concentration. Our experimental results reveal that ultrasonic humidifiers can produce significant quantities of $\mathrm{H}_{2} \mathrm{O}_{2}$ in their mist (and also in the water reservoir), which then appears in the condensed water droplets. On the contrary, heating water to form vapor and condensing it does not produce $\mathrm{H}_{2} \mathrm{O}_{2}$ within our detection limits $(\geq 0.25 \mu \mathrm{M})$ (image credit, Ivan Gromicho, KAUST).

MVD100E) using protocols that we have reported previously. ${ }^{39}$

Characterizing Wetting of Substrates via Apparent Contact Angles. Apparent contact angles of water droplets were measured on the substrates using the Kruss Drop Shape Analyzer (DSA100E), and the data were analyzed with the Advance software.

Glovebox Experiments. Condensation experiments were performed inside a portable isolation glovebox (Cleatech, catalog no. 2200-2-B) as a controlled-environment chamber. It was equipped with a digital humidity control system (Cleatech, A21-HM-HDS) that purged nitrogen gas flow to dehumidify the air. $\mathrm{SiO}_{2} / \mathrm{Si}$ wafers with the surface treatments mentioned above were used as substrates. The substrates were cooled by placing them onto an ice-water bag, i.e., ice mixed with water such that the temperature of the bag is constant in every region. We allowed the samples to reach thermal equilibrium with the ice-water bath. The temperature of the surfaces was measured via a noncontact digital infrared thermometer (Lasergrip 774) during the experiment. The relative humidity inside the chamber was kept in the range of $92-96 \%$, and the laboratory temperature was in the range of $21-23{ }^{\circ} \mathrm{C}$. To collect the samples after condensation, we poured the droplets into clean glassware and transferred it into a $15 \mathrm{~mL}$ centrifuge tube (VWR International).

Water Vapor Generation via an Ultrasonic Humidifier. The following two ultrasonic humidifiers were used in this work: (i) Proton PHC 9UH (15 W) and (ii) Beurer LB $44(20 \mathrm{~W})$. Both of them contain a piezoelectric disk that vibrates creating ultrasonic waves that lead to the formation of mist from bulk water. The former humidifier was used in most of our experiments. To prevent the direct deposition of the mist (before its evaporation) onto the substrates, we positioned them $40 \mathrm{~cm}$ apart. These humidifiers enabled us to pinpoint the effect of output power on $\mathrm{H}_{2} \mathrm{O}_{2}$ production in the mist, the water reservoirs, and the condensates.

Water Vapor Generation via a Heating Plate. Deionized water was heated in the range of $50-70{ }^{\circ} \mathrm{C}$ using an IKA RCT heating plate (catalog no. 3810000). The plate was located $\sim 30 \mathrm{~cm}$ from the substrates. To control the temperature, the coupled temperature sensor (PT 1000.60) was inserted inside the water.

Quantification of $\mathrm{H}_{2} \mathrm{O}_{2}$ in Water. Hydrogen Peroxide Assay Kit (HPAK) Assay. The $\mathrm{H}_{2} \mathrm{O}_{2}$ concentration inside condensed water microdroplets was quantified using the HPAK (fluorometric-near infrared, catalog no. ab138886). It contains its unique AbIR Peroxidase Indicator that produces fluorescence independent of the solution $\mathrm{pH}$ in the range of 4-10. Its maximum excitation wavelength is at $647 \mathrm{~nm}$, and its maximum emission at $674 \mathrm{~nm}$. Horseradish peroxidase catalyzes the reaction between $\mathrm{H}_{2} \mathrm{O}_{2}$ and the indicator and enhances the fluorescence signal. This facilitates the linear range of detection from $250 \mathrm{nM}$ to $10 \mu \mathrm{M}$. The calibration curve (Figure 1C) was realized by adding $50 \mu \mathrm{L}$ of an $\mathrm{H}_{2} \mathrm{O}_{2}$ standard solution from a concentration of $50 \mathrm{nM}$ to $10 \mu \mathrm{M}$ to $50 \mu \mathrm{L}$ of the $\mathrm{H}_{2} \mathrm{O}_{2}$ reaction mixture. The analysis was performed in a 96-well black/clear bottom microtiter plate with the SpectraMax M3 microplate reader (Molecular Devices LLC). The analysis software used was SoftMax Pro 7. The water microdroplets were analyzed in the same way by mixing $50 \mu \mathrm{L}$ of each sample with the $\mathrm{H}_{2} \mathrm{O}_{2}$ reaction mixture, thus obtaining the respective concentration by the calibration curve.

Peroxide Test Strips for Semiquantitative Analysis. Peroxide test strips (Baker Test Strips, VWR International) with a detection limit of $1-100 \mathrm{mg} / \mathrm{L}$ were used to analyze the $\mathrm{H}_{2} \mathrm{O}_{2}$ concentration when we could not collect adequate sample volumes $(100 \mu \mathrm{L})$ for HPAK analysis. These strips contain a 
colorimetric reagent that turns blue when brought into contact with $\mathrm{H}_{2} \mathrm{O}_{2}$ in the specified concentration range.

Characterization of the Size of Microdroplets. After microdroplet condensation inside the chamber, the samples were quickly $(<10 \mathrm{~s})$ moved to a Leica DVM6 optical microscope for imaging. Next, Image ${ }^{24}$ was used to estimate the size distribution. To estimate the size distributions of microdroplets condensed from the ambient laboratory air, substrates were already positioned in the microscope.

Probe Sonication. A $500 \mathrm{~W}$ ultrasonic processor (Sonics \& Materials, model VC 505) with a stepped microtip was used to ultrasonicate $30 \mathrm{~mL}$ of water at $20 \mathrm{kHz}$ at its $40 \%$ amplitude for different durations from 10 to $180 \mathrm{~min}$. The beaker was kept in an ice bath to prevent sample evaporation.

\section{ASSOCIATED CONTENT}

\section{SI Supporting Information}

The Supporting Information is available free of charge at https://pubs.acs.org/doi/10.1021/acs.jpclett.1c02953.

Comparative spectra for the $\mathrm{H}_{2} \mathrm{O}_{2}$ detection methods, wetting characterization of the treated $\mathrm{SiO}_{2} / \mathrm{Si}$ wafers, time-dependent size distribution images and analysis of condensed water droplets on FDTS-coated silica surfaces with $\mathrm{RH}$ realized via heating water to $60{ }^{\circ} \mathrm{C}$ in ambient air, comparison of $\mathrm{H}_{2} \mathrm{O}_{2}$ concentrations in the water droplets that accumulated on the substrates after the condensation of vapor produced via heating water in the temperature range of $50-70{ }^{\circ} \mathrm{C}, \mathrm{H}_{2} \mathrm{O}_{2}$ production in a bulk water sample using probe sonication, and assessment of $\mathrm{H}_{2} \mathrm{O}_{2}$ detection with HPAK from diluted condensed microdroplets (PDF)

\section{AUTHOR INFORMATION}

\section{Corresponding Author}

Himanshu Mishra - Interfacial Lab (iLab), King Abdullah University of Science and Technology (KAUST), Biological and Environmental Science and Engineering (BESE) Division, Water Desalination and Reuse Center (WDRC), Thuwal 23955-6900, Saudi Arabia; (1) orcid.org/00000001-8759-7812; Email: Himanshu.Mishra@kaust.edu.sa

\section{Authors}

Nayara H. Musskopf - Interfacial Lab (iLab), King Abdullah University of Science and Technology (KAUST), Biological and Environmental Science and Engineering (BESE) Division, Water Desalination and Reuse Center (WDRC), Thuwal 23955-6900, Saudi Arabia

Adair Gallo, Jr. - Interfacial Lab (iLab), King Abdullah University of Science and Technology (KAUST), Biological and Environmental Science and Engineering (BESE) Division, Water Desalination and Reuse Center (WDRC), Thuwal 23955-6900, Saudi Arabia; orcid.org/00000001-5015-8111

Peng Zhang - Interfacial Lab (iLab), King Abdullah University of Science and Technology (KAUST), Biological and Environmental Science and Engineering (BESE) Division, Water Desalination and Reuse Center (WDRC), Thuwal 23955-6900, Saudi Arabia

Jeferson Petry - Interfacial Lab (iLab), King Abdullah University of Science and Technology (KAUST), Biological and Environmental Science and Engineering (BESE)
Division, Water Desalination and Reuse Center (WDRC), Thuwal 23955-6900, Saudi Arabia

Complete contact information is available at:

https://pubs.acs.org/10.1021/acs.jpclett.1c02953

\section{Author Contributions}

${ }^{\dagger}$ N.H.M., A.G., and P.Z. contributed equally to this work.

Notes

The authors declare no competing financial interest.

\section{ACKNOWLEDGMENTS}

The authors acknowledge research funding from King Abdullah University of Science and Technology via Grant BAS/1/1070-01-01. The illustration for Figure 6 was created by Ivan Gromicho, Scientific Illustrator, Research Communication and Publication Services, Office of the Vice President for Research, King Abdullah University of Science and Technology.

\section{REFERENCES}

(1) Lee, J. K.; Han, H. S.; Chaikasetsin, S.; Marron, D. P.; Waymouth, R. M.; Prinz, F. B.; Zare, R. N. Condensing water vapor to droplets generates hydrogen peroxide. Proc. Natl. Acad. Sci. U. S. A. 2020, 117 (49), 30934-30941.

(2) Seinfeld, J. H.; Pandis, S. N. Atmospheric Chemistry and Physics: From Air Pollution to Climate Change, 2nd ed.; Wiley-Interscience, 1998.

(3) Gunz, D. W.; Hoffmann, M. R. Atmospheric chemistry of peroxides: a review. Atmos. Environ., Part A 1990, 24 (7), 1601-1633.

(4) He, S. Z.; Chen, Z. M.; Zhang, X.; Zhao, Y.; Huang, D. M.; Zhao, J. N.; Zhu, T.; Hu, M.; Zeng, L. M. Measurement of atmospheric hydrogen peroxide and organic peroxides in Beijing before and during the 2008 Olympic Games: Chemical and physical factors influencing their concentrations. J. Geophys. Res. 2010, 115 (D17), n/a.

(5) Zhu, C.; Francisco, J. S. Production of hydrogen peroxide enabled by microdroplets. Proc. Natl. Acad. Sci. U. S. A. 2019, 116 (39), 19222.

(6) Otter, J. A.; Yezli, S.; Barbut, F.; Perl, T. M. An overview of automated room disinfection systems: When to use them and how to choose them. Decontamination in Hospitals and Healthcare 2020, 323369.

(7) Hoffmann, M.; Hua, I.; Hoechemer, R. Application of Ultrasonic Irradiation for the Degradation of Chemical Contaminants in Water. Ultrason. Sonochem. 1996, 3, 168-172.

(8) Marshall, M.; Cancro, L.; Fischman, S. Hydrogen Peroxide: A Review of Its Use in Dentistry. J. Periodontol. 1995, 66, 786-96.

(9) Dulay, M. T.; Huerta-Aguilar, C. A.; Chamberlayne, C. F.; Zare, R. N.; Davidse, A.; Vukovic, S. Effect of relative humidity on hydrogen peroxide production in water droplets. QRB Discovery 2021, 2, e8.

(10) Mishra, H.; Enami, S.; Nielsen, R. J.; Stewart, L. A.; Hoffmann, M. R.; Goddard, W. A.; Colussi, A. J. Bronsted basicity of the airwater interface. Proc. Natl. Acad. Sci. U. S. A. 2012, 109 (46), 1867918683.

(11) Saykally, R. J. Air/water interface: Two sides of the acid-base story. Nat. Chem. 2013, 5 (2), 82-84.

(12) Gallo, A.; Farinha, A. S. F.; Dinis, M.; Emwas, A.-H.; Santana, A.; Nielsen, R. J.; Goddard, W. A.; Mishra, H. The chemical reactions in electrosprays of water do not always correspond to those at the pristine air-water interface. Chemical Science 2019, 10 (9), 25662577.

(13) Colussi, A. J.; Enami, S. Comment on "The chemical reactions in electrosprays of water do not always correspond to those at the pristine air-water interface" by A. Gallo Jr, A. S. F. Farinha, M. Dinis, A.-H. Emwas, A. Santana, R. J. Nielsen, W. A. Goddard III and H. Mishra, Chem. Sci., 2019, 10, 2566. Chem. Sci. 2019, 10, 8253. 
(14) Gallo, A.; Farinha, A. S. F.; Emwas, A.-H.; Santana, A.; Nielsen, R. J.; Goddard, W. A.; Mishra, H. Reply to the 'Comment on "The chemical reactions in electrosprays of water do not always correspond to those at the pristine air-water interface"' by A. J. Colussi and S. Enami, Chem. Sci., 2019, 10, DOI: 10.1039/c9sc00991d. Chem. Sci. 2019, 10, 8256 .

(15) Nauruzbayeva, J.; Sun, Z.; Gallo, A.; Ibrahim, M.; Santamarina, J. C.; Mishra, H. Electrification at water-hydrophobe interfaces. Nat. Commun. 2020, 11 (1), 5285.

(16) Uematsu, Y.; Bonthuis, D. J.; Netz, R. R. Charged SurfaceActive Impurities at Nanomolar Concentration Induce Jones-Ray Effect. J. Phys. Chem. Lett. 2018, 9 (1), 189-193.

(17) Byrnes, S. J.; Geissler, P. L.; Shen, Y. R. Ambiguities in surface nonlinear spectroscopy calculations. Chem. Phys. Lett. 2011, 516 (46), $115-124$.

(18) Agmon, N.; Bakker, H. J.; Campen, R. K.; Henchman, R. H.; Pohl, P.; Roke, S.; Thämer, M.; Hassanali, A. Protons and Hydroxide Ions in Aqueous Systems. Chem. Rev. 2016, 116 (13), 7642-7672.

(19) Ruiz-Lopez, M. F.; Francisco, J. S.; Martins-Costa, M. T. C.; Anglada, J. M. Molecular reactions at aqueous interfaces. Nature Reviews Chemistry 2020, 4 (9), 459-475.

(20) Barreto, J. C.; Smith, G. S.; Strobel, N. H.; McQuillin, P. A.; Miller, T. A. Terephthalic acid: a dosimeter for the detection of hydroxyl radicals in vitro. Life Sci. 1994, 56 (4), PL89-PL96.

(21) Kim, G.; Lee, Y.-E. K.; Kopelman, R. Hydrogen Peroxide $\left(\mathrm{H}_{2} \mathrm{O}_{2}\right)$ Detection with Nanoprobes for Biological Applications: A Mini-review. In Oxidative Stress and Nanotechnology: Methods and Protocols; Armstrong, D., Bharali, D. J., Eds.; Humana Press: Totowa, NJ, 2013; pp 101-114.

(22) Pillai, S.; Santana, A.; Das, R.; Shrestha, B. R.; Manalastas, E.; Mishra, H. A molecular to macro level assessment of direct contact membrane distillation for separating organics from water. J. Membr. Sci. 2020, 608, 118140.

(23) Adamson, A. W.; Gast, A. P. Physical Chemistry of Surfaces; Wiley-Interscience, 1997.

(24) Schneider, C. A.; Rasband, W. S.; Eliceiri, K. W. NIH Image to ImageJ: 25 years of image analysis. Nat. Methods 2012, 9 (7), 671675.

(25) Gao, N.; Geyer, F.; Pilat, D.; Wooh, S.; Vollmer, D.; Butt, H.-J.; Berger, R. How drops start sliding over solid surfaces. Nat. Phys. 2018, 14, 191.

(26) Lee, J. K.; Walker, K. L.; Han, H. S.; Kang, J.; Prinz, F. B.; Waymouth, R. M.; Nam, H. G.; Zare, R. N. Spontaneous generation of hydrogen peroxide from aqueous microdroplets. Proc. Natl. Acad. Sci. U. S. A. 2019, 116 (39), 19294-19298.

(27) Suslick, K. S. Sonochemistry. Science 1990, 247 (4949), 143945 .

(28) Riesz, P.; Berdahl, D.; Christman, C. L. Free radical generation by ultrasound in aqueous and nonaqueous solutions. Environ. Health Perspect. 1985, 64, 233-252.

(29) Suslick, K. S. Ultrasound: its chemical, physical, and biological effects; VCH Publishers, 1988.

(30) Fang, X.; Mark, G.; von Sonntag, C. OH radical formation by ultrasound in aqueous solutions Part I: the chemistry underlying the terephthalate dosimeter. Ultrason. Sonochem. 1996, 3 (1), 57-63.

(31) Gonzalez-Avila, S. R.; Nguyen, D. M.; Arunachalam, S.; Domingues, E. M.; Mishra, H.; Ohl, C.-D. Mitigating cavitation erosion using biomimetic gas-entrapping microtextured surfaces (GEMS). Sci. Adv. 2020, 6 (13), eaax6192.

(32) Singh, R.; Tiwari, S.; Mishra, S. Cavitation Erosion in Hydraulic Turbine Components and Mitigation by Coatings: Current Status and Future Needs. J. Mater. Eng. Perform. 2012, 21, 1539.

(33) Gogate, P.; Tayal, R. K.; Pandit, A. Cavitation: A technology on the horizon. Current Science 2006, 91, 35-46.

(34) Petrier, C.; Lamy, M.-F.; Francony, A.; Benahcene, A.; David, B.; Renaudin, V.; Gondrexon, N. Sonochemical Degradation of Phenol in Dilute Aqueous Solutions: Comparison of the Reaction Rates at 20 and 487 kHz. J. Phys. Chem. 1994, 98 (41), 10514-10520.
(35) Hoffmann, M. R.; Hua, I.; Höchemer, R. Application of ultrasonic irradiation for the degradation of chemical contaminants in water. Ultrason. Sonochem. 1996, 3 (3), S163-S172.

(36) Ohl, C.-D.; Arora, M.; Dijkink, R.; Janve, V.; Lohse, D. Surface cleaning from laser-induced cavitation bubbles. Appl. Phys. Lett. 2006, 89 (7), 074102.

(37) Bang, J. H.; Suslick, K. S. Applications of Ultrasound to the Synthesis of Nanostructured Materials. Adv. Mater. 2010, 22 (10), 1039-1059.

(38) Milli- $Q{ }^{\circledR}$ Advantage A10® Water Purification Systems. Useradapted ultrapure water. EMD Millipore Corp.: Billerica, MA, 2013.

(39) Shrestha, B. R.; Pillai, S.; Santana, A.; Donaldson, S. H., Jr; Pascal, T. A.; Mishra, H. Nuclear Quantum Effects in Hydrophobic Nanoconfinement. J. Phys. Chem. Lett. 2019, 10 (18), 5530-5535. 